\title{
Multimorbidity and achievement of treatment goals among patients with type 2 diabetes: a primary care, real-world study
}

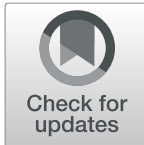

Eveliina Heikkala ${ }^{1,2,3^{*}}$, llona Mikkola ${ }^{1}$, Jari Jokelainen ${ }^{3}$, Markku Timonen ${ }^{3}$ and Maria Hagnäs ${ }^{1,2,3}$

\begin{abstract}
Background: Type 2 diabetes (T2D), with its prevalence and disability-causing nature, is a challenge for primary health care. Most patients with T2D are multimorbid, i.e. have one or more long-term diseases in addition to T2D. Multimorbidity may play a role in the achievement of T2D treatment targets, but is still not fully understood. The aims of the present cross-sectional, register-based study were to evaluate the prevalence and the most common patterns of multimorbidity among patients with T2D; and to study the potential associations between multimorbidity and treatment goal achievement, including measurements of glycosylated haemoglobin A1c (HbA1c), low-density lipoprotein (LDL) and systolic blood pressure (sBP).

Methods: The study population consisted of 4545 primary care patients who received a T2D diagnosis between January 2011 and July 2019 in Rovaniemi Health Centre, Finland. Data on seven long-term concordant (T2D-related) diseases, eight long-term discordant (non-T2D-related) diseases, potential confounders (age, sex, body mass index, prescribed medication), and the outcomes studied were collected from patients' records. Logistic regression models with odds ratios (ORs) and $95 \%$ confidence intervals (Cls) were assessed to determine the associations between multimorbidity and the achievement of treatment targets.
\end{abstract}

Results: Altogether, $93 \%$ of the patients had one or more diseases in addition to T2D, i.e. were considered multimorbid. Furthermore, $21 \%$ had only concordant disease(s) (Concordant subgroup), $8 \%$ had only discordant disease(s) (Discordant subgroup) and $64 \%$ had both (Concordant and discordant subgroup). As either single diseases or in combination with others, hypertension, musculoskeletal (MS) disease and hyperlipidaemia were the most prevalent multimorbidity patterns. Being multimorbid in general (OR 1.32, Cl 1.01-1.70) and belonging to the Concordant (OR 1.45, Cl 1.08-1.95) and Concordant and discordant (OR 1.31, Cl 1.00-1.72) subgroups was associated with achievement of the HbA1c treatment target. Belonging to the Concordant and discordant subgroup was related to meeting the LDL treatment target (OR 1.31, Cl 1.00-1.72).

Conclusions: Multimorbidity, including cardiovascular risk and the musculoskeletal disease burden, was extremely prevalent among the T2D patients who consulted primary health care. Primary care clinicians should survey the possible co-existence of long-term diseases among T2D patients to help maintain adequate treatment of T2D.

\footnotetext{
* Correspondence: mia.heikkala@oulu.fi

${ }^{1}$ Rovaniemi Health Center, Koskikatu 25, 96200 Rovaniemi, Finland

${ }^{2}$ Medical Research Center Oulu, University of Oulu and Oulu University

Hospital, PO Box 5000, 90014 Oulu, Finland

Full list of author information is available at the end of the article
}

\section{$\triangle B M C$}

(c) The Author(s). 2021 Open Access This article is licensed under a Creative Commons Attribution 4.0 International License, which permits use, sharing, adaptation, distribution and reproduction in any medium or format, as long as you give appropriate credit to the original author(s) and the source, provide a link to the Creative Commons licence, and indicate if changes were made. The images or other third party material in this article are included in the article's Creative Commons licence, unless indicated otherwise in a credit line to the material. If material is not included in the article's Creative Commons licence and your intended use is not permitted by statutory regulation or exceeds the permitted use, you will need to obtain permission directly from the copyright holder. To view a copy of this licence, visit http://creativecommons.org/licenses/by/4.0/. The Creative Commons Public Domain Dedication waiver (http://creativecommons.org/publicdomain/zero/1.0/) applies to the data made available in this article, unless otherwise stated in a credit line to the data. 


\section{Background}

Type 2 diabetes (T2D) is one of the most common and disability-causing long-term diseases worldwide [1]. Approximately $8 \%$ of the global population is estimated to suffer from T2D during their lifetime [2]. It is predicted that between 2010 and 2030, the number of people living with diabetes in developed countries will increase by $20 \%$ [3]. T2D is a metabolic disorder, which is associated with lifestyle and genetic factors [2, 4-6].

T2D rarely occurs without coexisting diseases. It has been reported that $77-90 \%$ of patients with T2D also have one or more other diseases and can therefore be categorised as multimorbid [7, 8]. Typical diseases that coexist with T2D are hypertension and cardiovascular diseases [8, 9], but different pains and mental health problems are also prevalent [7-9]. The presence of coexisting diseases associates with patients' unbeneficial selfcare behaviours [10], macrovascular complications, hospitalisation, and mortality among patients with T2D [11, 12]. A significant part of $\mathrm{T} 2 \mathrm{D}$ medical costs relate to complications and coexisting diseases [13].

In the prevention of T2D-related complications, it is essential that the treatment goals related to glucose, cholesterol, and blood pressure (BP) are achieved [14]. Despite the heightened risk of complications and mortality related to multimorbidity among patients with T2D $[11,12]$, the relevance of multimorbidity for achieving the goals of these clinical measures is not yet fully understood. Studies examining differentiating concordant (T2D-related) and discordant (non-T2D-related) diseases in multimorbidity patterns, as suggested by Piette \& Kerr [15], have observed that concordant conditions positively affect the achievement of measured treatment goals [16-19], whereas the relationships between discordant diseases and goal achievement seem to be more conflicting $[16,18,19]$. In a recent systematic review, ten of the 14 included studies found no associations between multimorbidity and glycosylated haemoglobin A1c (HbA1c), whereas four of the 14 studies related multimorbidity to higher levels of HbA1c [20]. However, not all studies have observed an association between concordant conditions and lower HbA1c [9]. Only a limited number of studies have explored the role of multimorbidity in the achievement of treatment goals using a number of diabetic treatment measurements (HbA1c, low-density-lipoprotein cholesterol (LDL), and BP). Studies conducted in a primary care setting [20], focusing only on patients with T2D are especially lacking [16-19].

To increase knowledge about multimorbidity among patients with T2D, we studied Northern Finnish T2D patients who consulted primary health care centres between 2011 and 2019. Our aims were to estimate the prevalence of multimorbidity; to evaluate which multimorbidity patterns are the most prevalent; and to assess whether multimorbidity is associated with the achievement of T2D treatment goals in a cross-sectional, realworld setting among Northern Finnish patients with T2D. We hypothesised that multimorbidity is extremely prevalent and that concordant diseases are positively, and discordant diseases negatively associated with achieving treatment goals for $\mathrm{HbA1c}$, LDL, and systolic $\mathrm{BP}(\mathrm{sBP})$.

\section{Methods}

\section{Study population and study protocol}

The study population included primary care patients who lived in the city of Rovaniemi, Finland and who had received a T2D diagnosis between January 2011 and July 2019. T2D diagnosis was based on the ICD-10 (10th revision of the World Health Organization's International Classification of Disease) codes E11.1-E11.9, which we found in the patient records of Rovaniemi's health centre. During the time of data collection, altogether 4545 people were recorded as having T2D. Patients with no visits to primary care between 2017 and 2019 were excluded from the analysis to ensure that patients still lived in Rovaniemi and were alive. In Rovaniemi, all patients with T2D who are treated at the health centre are regularly called for planned T2D consultations at an interval of a maximum of one and a half years. The sample used in the cross-sectional analyses consisted of the number of observations with a corresponding outcome variable; for example, $\mathrm{N}$ for associations between multimorbidity and HbA1c was 4480 .

Rovaniemi is a city in Northern Finland with approximately 62000 people living in both urban and rural areas. All collected personal data were pseudonymised by replacing identifiable information with ID codes and were gathered anonymously. As this was a register-based study, according to contemporary Finnish legislation, no written consent was required from the participants. The study protocol was approved by the Ethics Committee of the Lapland Central Hospital (05/2018).

\section{Definition of multimorbidity}

In the present study, multimorbidity was defined as the presence of one or more long-term disease in addition to T2D [21, 22]. Classification of long-term diseases as concordant and discordant diseases is presented in Table 1. Concordant diseases, which are thought to share a similar pathophysiology with T2D, were selected in line with earlier publications [7, 18]. To study cardiovascular diseases in general, we combined coronary heart disease, peripheral vascular disease, and stroke/TIA with cardiovascular diseases. The selection of discordant diseases, i.e. those not directly related to T2D, was based on their prevalence being $5 \%$ or over in the present study population, which is a commonly applied method to assign long-term diseases in 
Table 1 Classification of long-term diseases

\begin{tabular}{l}
\hline Disease(s) \\
\hline Concordant diseases \\
Hypertension \\
Hyperlipidaemia \\
Atrial Fibrillation \\
Heart Failure \\
Obesity \\
Chronic kidney disease \\
Cardiovascular diseases \\
Discordant diseases \\
Cancer \\
Musculoskeletal diseases \\
Asthma/chronic obstructive pulmonary disease \\
Hyperplasia of the prostate \\
Hypothyroidism \\
Dementia/Alzheimer's disease \\
Depression \\
Sleep disorders
\end{tabular}

multimorbidity studies [23]. Musculoskeletal (MS) diseases included osteoarthritis, back diseases, inflammatory polyarthropathies, and soft tissue diseases, as these were the most prevalent in this category (prevalence rate $>5 \%$ in the study sample) and are considered to be long term. Data on longterm diseases were collected from patient records using the corresponding ICD-10 codes.

\section{Outcomes}

The outcomes of the present study were the achievement of the below-mentioned treatment goals for HbA1c, LDL and sBP, which were dichotomised as yes vs. no. The latest values of all of these biochemical variables were applied and retrieved from patient records. Before a planned T2D consultation or during another BP check-up, patients were asked to measure their BP at home twice a day, twice per session, for 4 days [24]. The average of all sBP values was used. In the case of missing home measurements, we utilised the measurement data collected during the healthcare visit.

The targets of the above-mentioned biochemical variables were: $\mathrm{sBP}<135 \mathrm{mmHg}, \mathrm{HbA} 1 \mathrm{c}<53 \mathrm{mmol} / \mathrm{mol}$, and $\mathrm{LDL}<2.5 \mathrm{mmol} / \mathrm{L}$, in accordance with the latest Finnish national guidelines for the treatment of T2D [25]. As sBP values were monitored at home, the target was $<135 \mathrm{mmHg}$ instead of $<140 \mathrm{mmHg}$ as suggested in the national BP guideline [26].

\section{Covariates and variables used to characterise study population}

The analyses of the present study were adjusted for age, sex, body mass index (BMI) and prescribed medications, collected from patient records. Participants reported their weight and height in a document sent before a planned T2D consultation or in a BP check-up. BMI $\left(\mathrm{kg} / \mathrm{m}^{2}\right)$ was divided according to the World Health Organization's classification [27] as underweight/normal weight $(\mathrm{BMI}<25.0)$, overweight (25.0-29.9), obesity (BMI 30.0 or over), and unknown. Data on prescriptions of antihyperglycemic, antihypertensive, and lipid lowering medications were gathered 2 years before and after the latest value of a corresponding clinical value, i.e. prescription of antihyperglycemic medication 2 years before and after the latest HbA1c value. The medications included, according to the ATC (Anatomical Therapeutic Chemical) codes, were: A10B, oral diabetes medications; A10A, insulins; C09A, angiotensin-converting enzyme inhibitors; C09C, angiotensin receptor blockers; C07AB, beta blockers; C08CA, calcium blockers; C03, diuretics; C10AA, statins; and C10AX, ezetimibe. Estimated glomerular filtration rate (eGFR) was assessed as a biochemical measure of renal function and was also obtained from patient records.

\section{Statistical methods}

We regarded multimorbidity and its subgroups (Concordant, Discordant, and Concordant and discordant) as explanatory factors and the achievement of the treatment targets for HbA1c, LDL, and sBP as outcome factors. We used logistic regression analyses to test the potential associations between explanatory factors and outcome factors among patients with T2D, with odds ratios (ORs) and $95 \%$ confidence intervals (CIs). We adjusted Model 1 for age, sex, and prescribed medications, and Model 2 for BMI in addition to covariates of Model 1. We calculated mean and standard deviation (SD) for age and the biochemical variables used, and the categorical variables were presented as proportions. Mean differences between multimorbidity groups for continuous variables were tested by independent samples t-test and analysis of variance; and by Pearson Chi-square test for categorical variables. Statistical analyses used IBM SPSS Statistics for Macintosh, Version 24.0. Armonk, NY: IBM Corp. IBM Corp. Released 2016. A $p$-value $<0.05$ was considered statistically significant.

\section{Results}

\section{Characterisation of studied patients with T2D}

Of the 4545 patients with T2D, $46 \%$ were women (Table 2). The mean age of the participants was 70.9 (12.3 SD), and their mean BMI was 29.8 (6.03 SD) kg/ $\mathrm{m}^{2}$. The treatment goals for HbA1c, sBP, and LDL were achieved by $71 \%, 46 \%$, and $56 \%$ of patients with T2D, respectively. Almost all had been prescribed some antihyperglycemic medication (97\%), and over $75 \%$ of the 
Table $\mathbf{2}$ Characteristics of patients diagnosed with type 2 diabetes

\begin{tabular}{lll}
\hline & Values/percentages & N of observations \\
\hline Sex, female, \% & 46 & 4545 \\
Age, mean (SD) & $70.9(12.3)$ & 4545 \\
Body mass index, $\mathrm{kg} / \mathrm{m}^{2}$, mean (SD) & $29.8(6.03)$ & 3434 \\
Underweight/normal weight, \% & 17 & 781 \\
Overweight, \% & 29 & 1296 \\
Obesity, \% & 30 & 1357 \\
Unknown & 24 & 1111 \\
HbA1c, mmol/mol, mean (SD) & $49.5(13.4)$ & 4480 \\
sBP, mmHg, mean (SD) & $138(20.4)$ & 3394 \\
LDL, mmol/l, mean (SD) & $2.52(1.00)$ & 4423 \\
eGFR, ml/min/1.73m², mean (SD) & $78.2(20.4)$ & 4049 \\
Proportion of patients who achieved treatment target for & & 4480 \\
$\quad$ HbA1c (<53 mmol/mol), \% & 71 & 3394 \\
$\quad$ sBP (<135 mmHg), \% & 46 & 4423 \\
$\quad$ LDL (<2.5 mmol/l), \% & 56 & 4545 \\
Antihyperglycemic medication of any kind, \% & 97 & 4545 \\
Antihypertensive medication of any kind, \% & 75 & 4545 \\
Lipid lowering medication of any kind, \% & 88 & \\
\hline
\end{tabular}

HbA1c glycosylated haemoglobin A1c, SBP systolic blood pressure, LDL low-density-lipoprotein cholesterol, eGFR estimated glomerular filtration rate, $S D$ standard deviation

patients had also been prescribed antihypertensive, or lipid lowering medication of some kind.

\section{Prevalence of multimorbidity and characteristics of patients in multimorbidity groups}

The prevalence of multimorbidity was as high as $93 \%$ (Table 3). Of the multimorbidity subgroups, the most common group was Concordant and discordant (64\%), followed by Concordant (21\%) and Discordant (8\%). The number of diseases in addition to T2D was mainly between one and two across the subgroups, except in the Concordant and discordant subgroup (3; mean 3.89). Among the multimorbid patients, the mean number of diseases was 3.23. Those without multimorbidity were slightly younger than their multimorbid counterparts (mean 62.6 vs. 71.5 years, $p<0.001$ ). However, it is of note that the individuals without multimorbidity achieved the recommended levels of HbA1c (65\% vs. $71 \%, p=0.023)$ and LDL $(40 \%$ vs. $57 \%, p<0.001)$ less often than those with multimorbidity. We observed no significant differences between the age or sex of those with BMI data and those without, but slightly fewer patients without BMI data had achieved the HbAlc target (data not shown).

\section{Multimorbidity patterns}

Figure 1 presents the most common disease patterns, including one to three diseases in addition to T2D among the study population $(n=4545)$. Patients with T2D most commonly suffered from hypertension (71\%), an MS disease $(52 \%)$ or hyperlipidaemia $(50 \%)$. Over $40 \%$ of patients had hypertension combined with hyperlipidaemia or an MS disease, and nearly $30 \%$ were affected by hyperlipidaemia and an MS disease. One-quarter of the patients were diagnosed with all the following three diseases: hypertension, hyperlipidaemia and an MS disease. Depression was uncommon (6\%, data not shown).

\section{Associations between multimorbidity and T2D treatment targets}

Table 4 shows the ORs and CIs for the associations of multimorbidity and its subgroups with the achievement of the treatment goals for HbA1c, LDL and sBP. Being multimorbid and belonging to the Concordant and Concordant and discordant subgroups was significantly associated with the achievement of the HbAlc target in the fully adjusted model (OR 1.32, CI 1.01-1.70; OR 1.47, CI 1.10-1.95; OR 1.32, CI 1.01-1.72, respectively) and with the attainment of the LDL target in the model adjusted for age, sex and prescribed medications (OR 1.34, CI 1.03-1.74; OR 1.33, CI 1.00-1.78; OR 1.36, CI 1.051.78 , respectively). However, in the Concordant and discordant subgroup, only the association with meeting the LDL treatment target remained statistically significant when BMI was taken into account (OR 1.31, CI 1.001.72). Belonging to the Discordant subgroup did not 
Table 3 Prevalence and mean values of demographics in multimorbidity and type 2 diabetes (T2D) only groups

\begin{tabular}{|c|c|c|c|c|c|}
\hline & Multimorbidity & Concordant & Discordant & Concordant and discordant & T2D only \\
\hline$\%$ (n) of study population & 93 (4239) & $21(954)$ & $8(373)$ & $64(2912)$ & $7(306)$ \\
\hline Sex, female, \% (n) & $46(1960)$ & $39(372)$ & $53(197)$ & $48(1391)$ & $41(124)$ \\
\hline Age, mean (SD) & $71.5(12.0)$ & $68.9(11.7)$ & $65.6(14.6)$ & $73.1(11.3)$ & $62.6(12.9)$ \\
\hline Body mass index, $\mathrm{kg} / \mathrm{m}^{2}$, mean (SD) & $29.8(6.06)$ & $29.4(5.78)$ & $29.3(6.06)$ & $30.0(6.13)$ & $29.9(5.45)$ \\
\hline Under-/normal weight, \% (n) & $18(747)$ & $17(159)$ & $16(58)$ & $18(530)$ & $11(34)$ \\
\hline Overweight, \% (n) & $29(1237)$ & $28(266)$ & $26(98)$ & $30(873)$ & $19(59)$ \\
\hline Obesity, \% (n) & $30(1291)$ & $24(233)$ & $26(95)$ & $33(963)$ & $22(66)$ \\
\hline Unknown, \% (n) & $23(964)$ & $31(296)$ & $33(122)$ & $19(546)$ & $48(147)$ \\
\hline \multicolumn{6}{|c|}{ Proportion of patients who achieved treatment target for } \\
\hline $\mathrm{HbA1c} \%$ (n) & $71(2965)$ & $73(682)$ & $67(242)$ & $71(2041)$ & $65(193)$ \\
\hline $\mathrm{sBP}, \%(n)$ & $46(1490)$ & $47(290)$ & $50(130)$ & $45(1070)$ & $50(78)$ \\
\hline $\mathrm{LDL}, \%(n)$ & $57(2372)$ & $56(525)$ & $46(161)$ & $59(1686)$ & $40(115)$ \\
\hline \multicolumn{6}{|l|}{ Number of diseases, \% (n) } \\
\hline 0 & & & & & $100(308)$ \\
\hline 1 & $14(606)$ & $36(345)$ & $70(261)$ & & \\
\hline 2 & $21(881)$ & $42(396)$ & $23(84)$ & $14(401)$ & \\
\hline 3 & $25(1048)$ & $18(169)$ & $6(21)$ & $30(858)$ & \\
\hline 4 & $20(852)$ & $4(40)$ & $2(6)$ & $28(806)$ & \\
\hline 5 & $12(503)$ & $0.5(4)$ & $0.5(1)$ & $17(498)$ & \\
\hline 6 & $6(234)$ & & & $8(234)$ & \\
\hline 7 & $2(89)$ & & & $3(89)$ & \\
\hline 8 & $0.5(19)$ & & & $1(19)$ & \\
\hline 9 & $0.2(7)$ & & & $0.5(7)$ & \\
\hline Mean number of diseases (SD) & $3.23(1.55)$ & $1.91(0.86)$ & $1.40(0.69)$ & $3.89(1.33)$ & \\
\hline
\end{tabular}

Concordant includes T2D-related diseases, Discordant includes non-T2D-related diseases, and Concordant and discordant includes both Multimorbidity $=$ one or more diseases in addition to T2D

HbA1c glycosylated haemoglobin A1c, SBP systolic blood pressure, LDL low-density-lipoprotein cholesterol, SD standard deviation

relate to any outcome in any model, and we observed no associations between multimorbidity or its subgroups and the achievement of the sBP treatment goal.

\section{Discussion}

In this primary care, real-world study of 4545 patients with T2D, we observed that $93 \%$ had one or more additional diseases. The majority of the multimorbid patients had both concordant and discordant diseases. Of the concordant diseases, hypertension, and of the discordant diseases, MS diseases were the most commonly coexisting diseases, appearing as individual diseases or in combination with other (mainly concordant) diseases among the study population. Surprisingly, depression was not included in the most frequent multimorbidity patterns. Being multimorbid in general and having only concordant disease(s) or a combination of concordant and discordant diseases was associated with the achievement of the HbAlc treatment target. Having both concordant and discordant diseases was also related to the attainment of the LDL treatment target.

In the current study, almost all the T2D patients had one or more diseases in addition to T2D. This is in line with the prevalence rate reported among Australian primary care patients (90\%; [7]), but slightly higher than the rates among English (77\%; [8]), Croatian (78\%; [28]) and Danish patients $(80 \%$; [29]). We found no studies assessing the frequency of multimorbidity by evaluating several diseases among Scandinavian patients with T2D other than that of Pouplier et al. [29]. Typically, the differences in the prevalence rates affiliate with the different definitions of multimorbidity used, but these studies (except [28]) defined multimorbidity as having one or more diseases in addition to T2D, as determined in the current study. Thus, discrepancies in the estimates could be due to different disease patterns being included in the analyses. Most of our patients had diagnoses of both concordant and discordant diseases, and having only concordant disease(s) was more common than having 


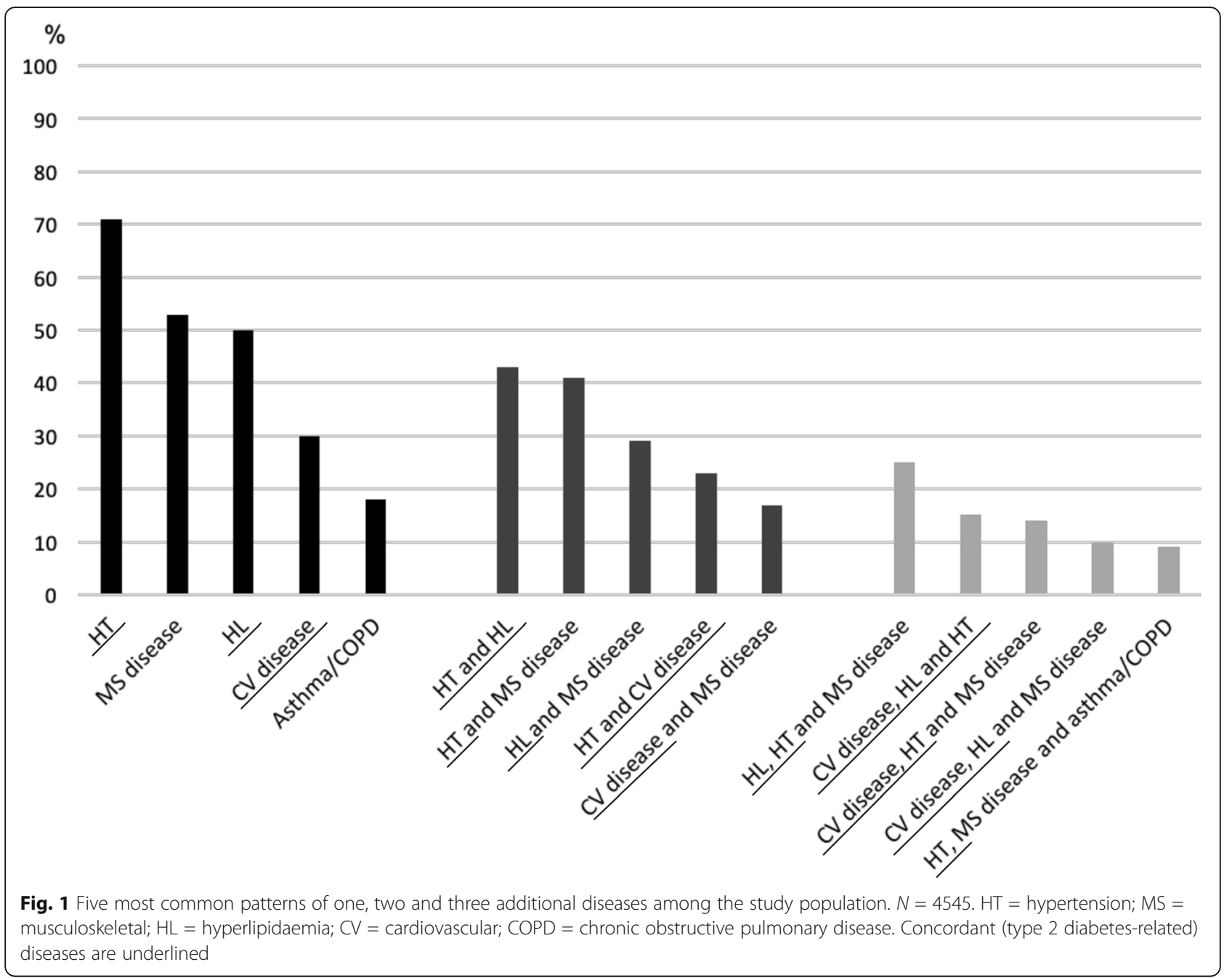

only discordant disease(s). Findings have been published that are both similar [19] and contradictory [7, 30].

MS diseases were highlighted in all the multimorbidity patterns with different numbers of additional diseases among the study sample. Congruently, Chiang et al. [7] found "painful conditions" to co-exist with T2D at a prevalence rate of $55 \%$, and Zghebi et al. [8] found osteoarthritis to be the third most common co-existing disease, with nearly one-fifth of T2D patients suffering from it. Being affected by an MS disease is likely to lead to a substantial disability burden and lower quality of life [31]. Along with its high prevalence, this emphasises the need to focus on possible MS disease symptoms among patients with T2D who consult primary care clinics. The generally high prevalence of MS diseases might explain its presence among T2D patients. On the other hand, a recent meta-analysis has shown that people with diabetes are more likely than those without diabetes to report different MS pains [32]. The co-existence of these two diseases might be accounted for by some metabolic/ inflammatory and biomechanical processes [33, 34] and/ or shared predisposing factors, such as obesity [35]. Our multimorbid patients did not significantly differ from the patients with T2D only with respect to BMI.

Surprisingly, depression was not presented in any of the most common multimorbidity patterns among the patients with T2D in the present study. This finding may be related to the low prevalence of depression, as only $6 \%$ of the participants were diagnosed with it (data not shown). In a recent systematic review and metaanalysis, the prevalence of depression among patients with T2D was estimated to be $28 \%$ worldwide and $24 \%$ in Europe [36]. Our study found a slightly higher prevalence when evaluations were based on self-reports (30\%) but its diagnosis-based frequency was still only $22 \%$. One explanation for this might be that depression diagnoses had not been properly recorded on the patients' registers. On the other hand, it might be that depression was underdiagnosed in our primary care population. A Spanish multicentre primary care study observed that 


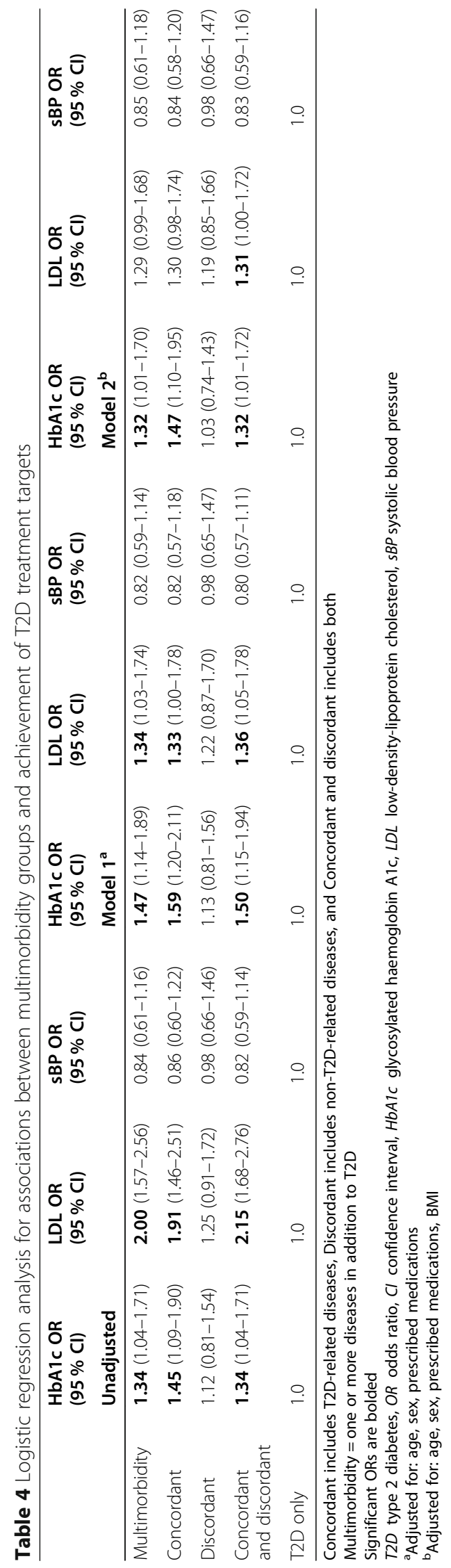


$12 \%$ of T2D patients had undiagnosed depression [37], and other studies from different clinics (not only primary care) have yielded similar percentages (17 and $18 \%)[38,39]$. Due to the increased mortality and cardiac event risks related to comorbid depression [40], and on the other hand, the favourable treatment outcomes of depression from glycaemic control [41], screening and treating depression among patients with T2D should definitely be a crucial part of T2D treatment.

Multimorbidity in general and T2D-related (concordant) diseases were associated with achievement of the HbA1c treatment target among the patients with T2D, but we observed no association with having only discordant diseases. Lin et al. [42] explored over 160,000 patients with T2D and observed that those with concordant diseases only or in combination with discordant disease(s) were more likely to achieve the HbA1c treatment target than those with T2D only. Similar findings have been reported in large studies assessing diabetes without separating type 1 and 2 [16, 19]. Furthermore, Magnan et al. [16] and Woodard et al. [19] showed significant associations between concordant diseases and the attainment of goals for cholesterol/LDL, but their findings with respect to BP target achievement were contradictory. According to our cross-sectional results, concordant diseases alone play no role in these outcomes among patients with T2D, but co-existence with discordant disease(s) seems to be relevant with respect to meeting the LDL target. The smaller significance of having discordant diseases only, in comparison to concordant diseases, for T2D treatment goal achievement has also been observed earlier in some diabetic populations [16, 18], although not in all [19]. Perhaps patients with concordant diseases are treated more efficiently and are more adherent to medication [10] than those with T2D or non-T2D-related diseases only, as they have other essential conditions that need to be at an optimal level to reduce the risks of T2D complications. However, this does not explain the smaller significance of concordant disease burden in the achievement of sBP treatment goals among patients with T2D, and further investigations are warranted.

The main strengths of the current study are its large primary care study population of patients with T2D, its real-world setting, and its reliable register-based data with no recall bias. Furthermore, the services of the municipal health care system of the city, like those of Finland in general, are low or moderate in cost and therefore the wealth of an individual is unlikely to hinder visits to physicians. To our knowledge, this is the first study to evaluate multimorbidity and its subgroups' relations to the achievement of $\mathrm{T} 2 \mathrm{D}$ treatment targets among a large set of Finnish patients with T2D. However, some limitations must also be acknowledged. One clear limitation of our study is related to the structure of the register data, which means that some diseases may be under-reported/-diagnosed, such as depression, the prevalence of which was lower than we expected $(6 \%$; data not shown). Due to the low rate of obesity, we also calculated and reported BMI. With respect to other limitations, the cross-sectional nature of the present study prevented us from making conclusions about the causeand-effect relationships between multimorbidity and achievement of T2D treatment goals. As we used a realworld clinical dataset, we had no data on lifestyle factors (except BMI), which can also be seen as a limitation. Some working-age patients with T2D may be treated by occupational health services only, and would thus not have been part of the present data. The data on prescribed medications were collected 2 years before and after the last clinical values of HbA1c, LDL and sBP, which may have led to the exclusion of some prescriptions. However, the defined timeline was considered to describe the best estimate of the current use of medications, as unfortunately, exact data were not available.

\section{Conclusions}

Multimorbidity is highly prevalent among patients with T2D. Diseases considered to be cardiovascular risk factors (hypertension and hyperlipidaemia) and MS diseases were emphasised in multimorbidity patterns. Multimorbidity in general and T2D-related concordant diseases alone or in combination with non-T2D-related discordant diseases were associated with the achievement of the HbA1c treatment goal, in comparison to T2D only. A combination of both concordant and discordant diseases was also related to meeting the LDL treatment goal, in comparison to T2D only. Clinicians working in primary care clinics should focus not only on patients with possible multimorbidity and morbidity including concordant diseases, but also on patients with T2D only, to provide support with their disease burden and maintain the targets of HbA1c and LDL treatment. In the future, the possible predictive role of multimorbidity in the achievement of treatment targets for T2D should be explored in a longitudinal setting. Similarly, attention should be paid to investigating different putative ways to improve the achievement of treatment targets among patients with T2D only.

\footnotetext{
Abbreviations

T2D: Type 2 diabetes; HbA1c: Glycosylated haemoglobin A1c; LDL: Lowdensity lipoprotein; BP: Blood pressure; sBP: Systolic blood pressure; OR: Odds ratio; Cl: Confidence interval; ICD-10: 10th revision of the World Health Organization's International Classification of Disease; COPD: Chronic obstructive pulmonary disease; MS: Musculoskeletal; BMl: Body mass index; ATC: Anatomical therapeutic chemical; eGFR: Estimated glomerular filtration rate; SD: Standard deviation
}

Acknowledgements

No acknowledgements. 


\section{Authors' contributions}

$\mathrm{EH}, \mathrm{IM}, \mathrm{J}$, and $\mathrm{MH}$ contributed to the study design. JJ performed the statistical analyses. EH drafted the manuscript. All authors participated in the interpretation of the data. IM, MT and MH assisted with the drafting of the manuscript. All authors approved the final version of the manuscript.

\section{Funding}

No funding.

\section{Availability of data and materials}

The data are not publicly available, to protect patients' confidentiality. All relevant data are presented in the article.

\section{Declarations}

\section{Ethics approval and consent to participate}

The study was approved by the Ethics Committee of the Lapland Centra Hospital. Patient consent for publication was not required.

\section{Consent for publication}

Not applicable.

\section{Competing interests}

The authors declare that they have no competing interests.

\section{Author details}

${ }^{1}$ Rovaniemi Health Center, Koskikatu 25, 96200 Rovaniemi, Finland. ${ }^{2}$ Medical Research Center Oulu, University of Oulu and Oulu University Hospital, PO Box 5000, 90014 Oulu, Finland. ${ }^{3}$ Center for Life Course Health Research, University of Oulu, PO Box 5000, 90015 Oulu, Finland.

\section{Received: 5 May 2021 Accepted: 7 September 2021}

\section{Published online: 14 September 2021}

\section{References}

1. GBD 2017 Disease and Injury Incidence and Prevalence Collaborators. Global, regional, and national incidence, prevalence, and years lived with disability for 354 diseases and injuries for 195 countries and territories, 1990-2017: a systematic analysis for the Global Burden of Disease Study 2017. Lancet. 2018;392(10159):1789-858. https://doi.org/10.1016/S0140-673 6(18)32279-7.

2. Zheng Y, Ley SH, Hu FB. Global aetiology and epidemiology of type 2 diabetes mellitus and its complications. Nat Rev Endocrinol. 2018;14(2):8898. https://doi.org/10.1038/nrendo.2017.151.

3. Shaw JE, Sicree RA, Zimmet PZ. Global estimates of the prevalence of diabetes for 2010 and 2030. Diabetes Res Clin Pract. 2010;87(1):4-14. https:// doi.org/10.1016/j.diabres.2009.10.007.

4. Bellou V, Belbasis L, Tzoulaki I, Evangelou E. Risk factors for type 2 diabetes mellitus: an exposure-wide umbrella review of meta-analyses. PLoS One. 2018:13(3):e0194127. https://doi.org/10.1371/journal.pone.0194127.

5. Mahajan A, Taliun D, Thurner M, Robertson NR, Torres JM, Rayner NW, et al. Fine-mapping type 2 diabetes loci to single-variant resolution using highdensity imputation and islet-specific epigenome maps. Nat Genet. 2018;50: 1505-13. https://doi.org/10.1038/s41588-018-0241-6.

6. Zhang Y, Pan XF, Chen J, Xia L, Cao A, Zhang Y, et al. Combined lifestyle factors and risk of incident type 2 diabetes and prognosis among individuals with type 2 diabetes: a systematic review and meta-analysis of prospective cohort studies. Diabetologia. 2020;63(1):21-33. https://doi.org/1 0.1007/s00125-019-04985-9.

7. Chiang JI, Furler J, Mair F, Jani BD, Nicholl Bl, Thuraisingam S, et al. Associations between multimorbidity and glycaemia ( $\mathrm{HbA1c}$ ) in people with type 2 diabetes: cross-sectional study in Australian general practice. BMJ Open. 2020;10:e039625. https://doi.org/10.1136/bmjopen-2020-039625.

8. Zghebi SS, Steinke DT, Rutter MK, Ashcroft DM. Eleven-year multimorbidity burden among 637255 people with and without type 2 diabetes: a population-based study using primary care and linked hospitalisation data. BMJ Open. 2020;10:e033866. https://doi.org/10.1136/bmjopen-2019-033866.

9. Chiang JI, Hanlon P, Li TC, Jani BD, Manski-Nankervis JA, Furler J, et al. Multimorbidity, mortality, and HbA1C in type 2 diabetes: a cohort study with UK and Taiwanese cohorts. PLoS Med. 2020;17(5):e1003094. https://doi. org/10.1371/journal.pmed.1003094.
10. Aga F, Dunbar SB, Kebede T, Gary RA. The role of concordant and discordant comorbidities on performance of self-care behaviors in adults with type 2 diabetes: a systematic review. Diabetes Metab Syndr Obes. 2019;12:333-56. https://doi.org/10.2147/DMSO.S186758.

11. Al-Musawe L, Martins AP, Raposo JF, Torre C. The association between polypharmacy and adverse health consequences in elderly type 2 diabetes mellitus patients; a systematic review and meta-analysis. Diabetes Res Clin Pract. 2019;155:107804. https://doi.org/10.1016/j.diabres.2019.107804.

12. McCoy RG, Lipska KJ, Van Houten HK, Shah ND. Association of cumulative multimorbidity, glycemic control, and medication use with hypoglycemiarelated emergency department visits and hospitalizations among adults with diabetes. JAMA Netw Open. 2020;3(1):e1919099. https://doi.org/10.1 001/jamanetworkopen.2019.19099.

13. Li R, Bilik D, Brown MB, Zhang P, Ettner SL, Ackermann RT, et al. Medical costs associated with type 2 diabetes complications and comorbidities. Am J Manag Care. 2013;19(5):421-30.

14. American Diabetes Association. Diabetes Care. 2019;42(Supplement 1):S10323. https://doi.org/10.2337/dc19-S010.

15. Piette JD, Kerr EA. The impact of comorbid chronic conditions on diabetes care. Diabetes Care. 2006;29(3):725-31. https://doi.org/10.2337/diacare.29.03. 06.dc05-2078.

16. Magnan EM, Palta M, Johnson HM, Bartels CM, Schumacher JR, Smith MA. The impact of a patient's concordant and discordant chronic conditions on diabetes care quality measures. J Diabetes Complications. 2015;29(2):288-94. https://doi.org/10.1016/j.jdiacomp.2014.10.003.

17. Magnan EM, Bolt DM, Greenlee RT, Fink J, Smith MA. Stratifying patients with diabetes into clinically relevant groups by combination of chronic conditions to identify gaps in quality of care. Health Serv Res. 2018;53(1): 450-68. https://doi.org/10.1111/1475-6773.12607.

18. Ricci-Cabello I, Stevens S, Kontopantelis E, Dalton AR, Griffiths RI, Campbell $J$, et al. Impact of the prevalence of concordant and discordant conditions on the quality of diabetes care in family practices in England. Ann Fam Med. 2015;13(6):514-22. https://doi.org/10.1370/afm.1848

19. Woodard LD, Urech T, Landrum CR, Wang D, Petersen LA. Impact of comorbidity type on measures of quality for diabetes care. Med Care. 2011; 49(6):605-10. https://doi.org/10.1097/MLR.0b013e31820f0ed0.

20. Chiang Jl, Jani BD, Mair FS, Nicholl Bl, Furler J, O'Neal D, et al. Associations between multimorbidity, all-cause mortality and glycaemia in people with type 2 diabetes: a systematic review. PLoS One. 2018;13(12):e0209585. https://doi.org/10.1371/journal.pone.0209585.

21. Nguyen H, Manolova G, Daskalopoulou C, Vitoratou S, Prince M, Prina AM. Prevalence of multimorbidity in community settings: a systematic review and meta-analysis of observational studies. J Comorb. 2019;9:1-15. https:// doi.org/10.1177/2235042X19870934.

22. Willadsen TG, Bebe A, Koster-Rasmussen R, Jarbol DE, Guassora AD, Waldorff $\mathrm{FB}$, et al. The role diseases, risk factors and symptoms in the definition of multimorbidity - a systematic review. Scan J Prim Health Care. 2016;34(2): 112-21. https://doi.org/10.3109/02813432.2016.1153242.

23. Diederich $\mathrm{C}$, Berger $\mathrm{K}$, Bartels B. The measurement of multiple chronic diseases - a systematic review on existing multimorbidity indices. J Gerontol A Biol Sci Med Sci. 2011;66(3):301-11. https://doi.org/10.1093/ gerona/glq208.

24. Parati G, Stergiou GS, Asmar R, Bilo G, de Leeuw P, Imai Y, et al. European society of hypertension guidelines for blood pressure monitoring at home: a summary report of the second international consensus conference on home blood pressure monitoring. J Hypertens. 2008;26(8):1505-26. https:// doi.org/10.1097/HJH.0b013e328308da66.

25. Type 2 diabetes. Current Care Guidelines. Working groups set up by the Finnish Medical Society Duodecim, the Finnish Society of Internal Medicine, the Medical Advisory Board of the Finnish Diabetes Society. Helsinki: The Finnish Medical Society Duodecim, 2020 (referred April, 6, 2021). Available online at: www.kaypahoito.fi

26. Hypertension. Current Care Guidelines. Working groups set up by the Finnish Medical Society Duodecim, the Finnish Hypertension Society. Helsinki: The Finnish Medical Society Duodecim, 2020 (referred April, 6, 2021). Available online at: www.kaypahoito.fi

27. World Health Organization. Obesity: Preventing and Managing the Global Epidemic: Report on a WHO Consultation (WHO Technical Report Series 894). Geneva: World Health Organization; 2000.

28. Lang VB, Marković BB. Prevalence of comorbidity in primary care patients with type 2 diabetes and its association with elevated $\mathrm{HbA1c}$ : a cross- 
sectional study in Croatia. Scand J Prim Health Care. 2016;34(1):66-72. https://doi.org/10.3109/02813432.2015.1132886.

29. Pouplier S, Olsen MÅ, Willadsen TG, Sandholdt H, Siersma V, Andersen CL, et al. The development of multimorbidity during 16 years after diagnosis of type 2 diabetes. J Comorb. 2018;8(1):2235042X18801658. https://doi.org/1 $0.1177 / 2235042 \times 18801658$.

30. Lin P-J, Pope E, Zhou FL. Comorbidity type and health care costs in type 2 diabetes: a retrospective database analysis. Diabetes Ther. 2018;9:1907-18. https://doi.org/10.1007/s13300-018-0477-2

31. Duffield SJ, Ellis BM, Goodson N, Walker-Bone K, Conaghan PG, Margham T, et al. The contribution of musculoskeletal disorders in multimorbidity: implications for practice and policy. Best Pract Res Clin Rheumatol. 2017; 31(2):129-44. https://doi.org/10.1016/j.berh.2017.09.004

32. Pozzobon D, Ferreira PH, Dario AB, Almeida L, Vesentini G, Harmer AR, et al. Is there an association between diabetes and neck and back pain? A systematic review with meta-analyses. PLoS One. 2019;14(2):e0212030. https://doi.org/10.1371/journal.pone.0212030.

33. Berenbaum F. Diabetes-induced osteoarthritis: from a new paradigm to a new phenotype. Ann Rheum Dis. 2011;70(8):1354-6. https://doi.org/10.1136/ pgmj.2010.146399.

34. Cannata F, Vadalà G, Ambrosio L, Fallucca S, Napoli N, Papalia R, et al. Intervertebral disc degeneration: a focus on obesity and type 2 diabetes. Diabetes Metab Res Rev. 2020;36(1):e3224. https://doi.org/10.1002/ dmrr.3224.

35. Guh DP, Zhang W, Bansback N, Amarsi Z, Birmingham CL, Anis AH. The incidence of co-morbidities related to obesity and overweight: a systematic review and meta-analysis. BMC Public Health. 2009;9:88. https://doi.org/1 0.1186/1471-2458-9-88

36. Khaledi M, Haghighatdoost F, Feizi A, Aminorroaya A. The prevalence of comorbid depression in patients with type 2 diabetes: an updated systematic review and meta-analysis on huge number of observational studies. Acta Diabetol. 2019;56(6):631-50. https://doi.org/10.1007/s00592-01 9-01295-9.

37. Cols-Sagarra C, López-Simarro F, Alonso-Fernández M, Mancera-Romero J, Pérez-Unanua MP, Mediavilla-Bravo JJ, et al. Work Group of Diabetes SEMERGEN (Sociedad Española de Médicos de Atención Primaria). Prevalence of depression in patients with type 2 diabetes attended in primary care in Spain. Prim Care Diabetes. 2016;10(5):369-75. https://doi. org/10.1016/j.pcd.2016.02.003.

38. Alajmani DSA, Alkaabi AM, Alhosani MW, Folad AA, Abdouli FA, Carrick FR, et al. Prevalence of undiagnosed depression in patients with type 2 diabetes. Front Endocrinol (Lausanne). 2019;10:259. https://doi.org/10.3389/ fendo.2019.00259.

39. Udedi M, Pence BW, Stewart RC, Muula AS. Detection and prevalence of depression among adult type 2 diabetes mellitus patients attending noncommunicable diseases clinics in Lilongwe, Malawi. Int J Ment Health Syst. 2020;14(1):79. https://doi.org/10.1186/s13033-020-00413-3.

40. Faroogi A, Khunti K, Abner S, Gillies C, Morriss R, Seidu S. Comorbid depression and risk of cardiac events and cardiac mortality in people with diabetes: a systematic review and meta-analysis. Diabetes Res Clin Pract. 2019;156:107816. https://doi.org/10.1016/j.diabres.2019.107816.

41. van der Feltz-Cornelis C, Allen SF, Holt RIG, Roberts R, Nouwen A, Sartorius N. Treatment for comorbid depressive disorder or subthreshold depression in diabetes mellitus: systematic review and meta-analysis. Brain Behav. 2021; 11(2):e01981. https://doi.org/10.1002/brb3.1981.

42. Lin P-J, Kent DM, Winn AN, Cohen JT, Neumann PJ. Multiple chronic conditions in type 2 diabetes mellitus: prevalence and consequences. Am J Manag Care. 2015;21(1):e23-34

\section{Publisher's Note}

Springer Nature remains neutral with regard to jurisdictional claims in published maps and institutional affiliations.

Ready to submit your research? Choose BMC and benefit from:

- fast, convenient online submission

- thorough peer review by experienced researchers in your field

- rapid publication on acceptance

- support for research data, including large and complex data types

- gold Open Access which fosters wider collaboration and increased citations

- maximum visibility for your research: over $100 \mathrm{M}$ website views per year

At $\mathrm{BMC}$, research is always in progress.

Learn more biomedcentral.com/submissions 